\title{
SUKCES SPEKTAKLI PERSONA. MARILYN I WYCINKA KRYSTIANA LUPY W CHINACH - ANALIZA ZJAWISKA NA PODSTAWIE RELACJI ORGANIZATORÓW
}

\section{Wstęp}

Spektakle Krystiana Lupy Persona. Marilyn i Wycinka zostały wystawione w Chinach w latach 2014-2015. Okazały się wielkim sukcesem, o czym świadczą zarówno relacje organizatorów, jak i recenzje prasowe chińskiej krytyki teatralnej. Jedne i drugie są warte omówienia dla pełnej prezentacji recepcji przedstawień polskiego reżysera w Państwie Środka. Ponieważ jednak objętość artykułu jest ograniczona, zdecydowałam się podzielić analizowane zagadnienie na dwie części. Niniejsza część zatem zostanie poświęcona ocenie spektakli Lupy na podstawie relacji organizatorów wydarzenia, zaś część druga ukaże się w kolejnym zeszycie „Gdańskich Studiów Azji Wschodniej”.

Głównym celem moich badań była odpowiedź na pytanie, co przyczyniło się do szczególnie gorącego odbioru sztuk Krystiana Lupy w Państwie Środka. Zjawisko to przeanalizowałam, po pierwsze, na podstawie działań organizacyjnych i marketingowych Instytutu Adama Mickiewicza w zakresie Projektu Azja (badania te stanowią treść pierwszej części artykułu), po drugie, dokonując próby rozpoznania rzeczywistych potrzeb repertuarowych chińskiego widza oraz oceny wrażliwości tego widza na teatr europejski na podstawie recenzji, które pojawiły się po pokazach (ten obszar badań został opisany w drugiej części artykułu).

Nim przejdę do właściwych rozważań związanych z zagadnieniami poruszonymi w niniejszej części, warto poczynić kilka uwag ogólnych, stanowiących wprowadzenie do całości. Konieczne wydaje się bowiem, by choćby w kilku zdaniach nakreślić, jak kształtowała się wiedza na temat współczesnego teatru europejskiego w Chinach na przestrzeni ostatniego stulecia ${ }^{1}$. Nie jest niczym nowym, że w kraju, w którym dyktatura partii komunistycznej próbuje kontrolować wszystkie obszary życia społecznego ${ }^{2}$, zachodnie twory kultury jako nośniki wolności artystycznej stanowią

Bardziej szczegółowo wątek ten opisuję w drugiej części artykułu.

2 M. Tian, The Poetics of Difference and Displacement: Twentieth-Century Chinese-Western Intercultural Theatre, Hong Kong 2008. 
swego rodzaju zagrożenie ${ }^{3}$. Recepcja kultury Zachodu staje się trudniejsza także z uwagi na kilka innych czynników, jak: naturalne, geograficzne zamknięcie Państwa Środka, od wieków przenikający wszystkie sfery życia Chińczyków konfucjanizm, konflikty z Zachodem i zrodzona podczas przyjmowania misji jezuickich, a później nieustannie rosnąca podejrzliwość wobec wszystkiego, co obce, aż w końcu metaforyczny wąż, który sam siebie zjada, czyli rewolucja kulturalna. Jeśli na wspomniane warunki nałożyć barierę językową i wynikającą z niej nieprzekładalność środków artystycznych, to wydaje się niemożliwe, aby współczesna europejska twórczość teatralna, zwłaszcza ta, której wartość jest efektem dążenia do możliwie głębokiego zrozumienia własnych korzeni, mogła być zrozumiała dla widzów wychowanych przede wszystkim na różnego rodzaju muzycznych gatunkach teatralnych. Celem badań nie jest polemika z wrażliwością chińskiego widza, ale zwrócenie uwagi na jego przyzwyczajenie do porozumiewania się środkami kultury kamuflażu oraz nawykowe patrzenie na świat przez pryzmat rodzimych archetypów i wartości.

Należy pamiętać również, że chiński dramat mówiony buaju pojawia się dopiero wraz z Ruchem 4 Maja i Ruchem Nowej Kultury ${ }^{4}$, a cała sztuka aktorstwa dramatycznego dociera z Rosji z początkiem lat 50. przez wąskie gardło cenzury, jaką narzuca świeżo ustanowiony rząd komunistyczny. W tym czasie europejskie środowiska teatralne przechodzą kolejny zwrot w stronę teatru awangardowego, czyli tzw. drugą reformę teatralną. Do Chin docierają zaledwie strzępy reformatorskich przedsięwzięć, w tym m.in. informacje o nowatorskim teatrze Kantora i Grotowskiego $^{5}$. Są to bodajże jedyne nazwiska polskich reżyserów, które będą znane szerszemu gronu przez kolejne dekady.

Mając świadomość tych nakładających się w czasie warunków, nasuwa się pytanie, na czym polega fenomen Krystiana Lupy w Chinach. Czy w ogóle można mówić o jakimś fenomenie, czy raczej o sukcesie marketingowym organizatorów wizyt teatru Lupy w Chinach? Czy dopuszczenie sztuki teatralnej Wycinka przez cenzurę to przypadek, czy raczej niezrozumienie treści? A może efekt tak ważnych w chińskiej kulturze znajomości? Czy recenzje, które pojawiły się w prasie oraz na licznych forach internetowych, to rzeczywiste próby analizy teatru Lupy czy kopie recenzji europejskich, a może powielane po stokroć słowa czołowych chińskich krytyków teatralnych? W końcu, jakie czynniki przyczyniły się do tak gorącego odbioru sztuk Lupy w Państwie Środka?

Jak zasygnalizowałam wyżej, pierwszą część artykułu poświęciłam działaniom Instytutu Adama Mickiewicza, w ramach których zostały zorganizowane pierwsze

3 K. Hellkötter, Europe-China Cultural Compass: Orientation for Cultural Cooperation Between China and Europe, Munich 2011.

4 L. Kasarełło, Recepcja dramaturgii europejskiej w okresie narodzin nowoczesnej kultury chinskiej, „Przegląd Orientalistyczny” 1995, nr 1-2.

5 R. Li, Mao's Chair: Revolutionizing Chinese Theatre, “Theatre Research International”, March 2002, vol. 27, no. 1. 
wyjazdy Krystiana Lupy do Chin. Istotna dla mnie jest odpowiedź na pytanie, dlaczego spośród wielu wybitnych polskich reżyserów wizytujących w Chinach to właśnie Krystian Lupa zapraszany jest tam najczęściej. Gdzie leży przyczyna gorącego przyjęcia Lupy w Chinach oraz gdzie ma swoje źródło rosnąca w siłę z każdym kolejnym pokazem fala medialnego zainteresowania reżyserem, której bezpośrednim przejawem są liczne recenzje oraz wywiady dla radia i telewizji? Pomocne w szukaniu odpowiedzi na te i wiele innych pytań będą przytoczone dalej najważniejsze wątki wywiadu, jaki udało mi się przeprowadzić z głównym managerem Projektu Azja, Marcinem Jacobym, oraz dane statystyczne dostępne dzięki raportom rocznym z działań Instytutu Adama Mickiewicza, które uzyskałam w drodze korespondencji.

\title{
Działania Instytutu Adama Mickiewicza promujące teatr polski w Azji
}

\begin{abstract}
Nie lubimy myśleć o sztuce w kategoriach marek, wizerunku kraju czy strategii promocyjnych. Wolimy postrzegać ja jako sferę wolności twórczej. Pytanie jednak, czy jedno wyklucza drugie? Źle wymyślone - może. Dobrze - przeciwnie: rozbudza twórców, pozwalając im konfrontować się z różnymi oczekiwaniami widowni, stylami odbioru i kontekstami, w jakie czasem ryzykownie popadają ich dzieła. Działanie dobrze wymyślone załatwia tematy z dziedziny marketingu w sposób elegancki i niewidoczny. Ale za tym niewidocznym stoi sztab bardzo konkretnych i ciężko pracujących ludzi z Instytutu Adama Mickiewicza.
\end{abstract}

- pisze dramaturg i teoretyk teatru Piotr Gruszczyński w przedmowie Teatrjako zwierze pociagowe do raportu sporządzonego przez Instytut Adama Mickiewicza „Polski teatr w Azji 2012-2016"." Idąc dalej za Gruszczyńskim, w ostatnich latach Instytut Adama Mickiewicza skupił się na budowaniu kulturalnego oblicza marki „Polska” na obszarze wyjątkowo trudnym, czyli w krajach Azji, które swoim potencjałem ekonomicznym dają zastrzyk energii starzejącej się Europie. Autor wstępu zauważa, jak karkołomnym zadaniem jest nawiązać prawdziwy, głęboki dialog między widzami a twórcami w tak odmiennej części świata i nie pozostać tylko egzotyczną atrakcją, a stać się prawdziwym partnerem do rozmowy. Zastanawia się w końcu, jak wciagnąć widzów z daleka w sprawy, które niekoniecznie ich dotyczą.

Większość z wyżej wymienionych pytań stała się podstawą do budowania założeń organizacyjnych i marketingowych Projektu Azja na kilka lat. Kilkuosobowy zespół projektu pod kierownictwem menadżera Marcina Jacoby’ego działał niezwykle skutecznie. Jako kurator sztuki z wieloletnim doświadczeniem Jacoby wiedział, że najszybsza droga do nawiązania współpracy prowadzi przez festiwale i targi sztuki,

“ Instytut Adama Mickiewicza, „Polski teatr w Azji 2012-2016”, s. 12, dokument uzyskany dzięki M. Jacoby'emu, menadżerowi Projektu Azja w Instytucie Adama Mickiewicza, drogą korespondencji elektronicznej. 
ale nie te odbywające się w Chinach kontynentalnych, tylko w demokratycznych krajach sąsiadujących bądź w rejonach autonomicznych Chińskiej Republiki Ludowej. Nic więc dziwnego, że pierwszym celem festiwalowym był Hongkong i Hong Kong Arts Festival, z którym Instytut Adama Mickiewicza rozpoczął współprace w 2012 r., w kolejnych latach dwukrotnie goszcząc dyrekcję programową festiwalu w Polsce na wizytach studyjnych. Jak czytamy w raporcie IAM, wizyty studyjne to niezwykle efektywne i wbrew pozorom niedrogie narzędzie. Zaproszenie do Polski selekcjonerów festiwali czy reżyserów z Azji daje im szansę zapoznania się z oferta kulturalną aktualną w danym roku, a menadżerom Projektu Azja szansę nawiązania osobistych relacji z „kluczowymi graczami”. Jak czytamy w raporcie:

Goście zapraszani na wizyty często podkreślają, że wyniesiona z nich wiedza pozwoliła im lepiej zrozumieć sztukę, która tu powstaje. Głębsze zrozumienie treści, choć ważne, to tylko jedna z korzyści, jakie płyną z organizacji wizyt studyjnych. Dzięki nim, znając swoją własna publiczność daleko lepiej niż nawet najlepszy ekspert zagraniczny, zagraniczni goście łatwiej podejmą trafne decyzje programowe dotyczące zapraszanych gości. IAM może bowiem przedstawić jedynie pewna paletę propozycji. Wybór zawsze jednak ostatecznie należy do gościa. (...) Nie przypadkiem najczęstszym gospodarzem naszych wizyt okazał się festiwal Boska Komedia. Jest on obecnie najszerszą prezentacja polskiego teatru w formie showcase'u, umożliwiająca gościom zapoznanie się w jednym miejscu z najnowszymi produkcjami z całego kraju. Wstępne rozmowy odbywają się zazwyczaj na gorąco, jeszcze w kuluarach krakowskiego festiwalu?

Dzięki tym działaniom w ramach Hong Kong Art Festival zaprezentowano dwie duże produkcje teatralne: 4.48 Psychosis w reżyserii Grzegorza Jarzyny oraz Opowieści afrykańskie $\mathrm{w}$ reżyserii Krzysztofa Warlikowskiego. Z kolei dzięki wizycie studyjnej przedstawiciela instytucji Hong Kong Leisure and Cultural Services Department, która zarządza większością obiektów kulturalnych i sportowych w Hongkongu, na World Culture Festival w 2013 r. zaproszono spektakl Persona. Marilyn Krystiana Lupy. W ten sposób realizacja zadań Projektu Azja nabrała tempa. Zaproszenie Lupy do Hongkongu miało ogromne znaczenie strategiczne, bo otworzyło drogę do dalszych prezentacji twórczości Lupy w Chinach, Japonii i Korei. W tym miejscu należy zaznaczyć, że działalność Instytutu doprowadziła do pokazów teatralnych wielu polskich reżyserów na chińskich scenach, ale w niniejszym artykule skupię się jedynie na spektaklach Krystiana Lupy wystawionych w Państwie Środka. Wybiórczo wspomnę więc o sylwetkach reżyserów, teoretyków teatru wizytujących w Chinach czy o samej strategii IAM, by dać obraz wydarzeń, które poprzedziły wyjazdy spektakli Lupy do Chin. I tak, pokazy Persony. Marilyn w Hongkongu zbiegły się w czasie z zapoznaniem osoby zarządzającej Tianjin Grand Theatre, który to teatr wówczas jeszcze był zupełnie nową instytucją mającą siedzibę niedaleko Pekinu, w mieście przemysłowym Tianjin.

\footnotetext{
Ibidem, s. 42.
} 
Zarządcą ledwie otwartego teatru okazał się znany pekiński menadżer kultury, dawny dyrektor Beijing Concert Hall, charyzmatyczny Qian Cheng. Dzięki niemu Persona. Marilyn jako pierwszy ze spektakli Lupy miał szansę zaprezentować się na deskach teatru w Tianjinie i stał się najważniejszym ogniwem w łańcuchu zdarzeń. Była to jednocześnie pierwsza tak duża pod względem liczebności widowni i rozmiaru sceny polska prezentacja teatralna w Chinach. W raporcie czytamy:

Spektakle Persony. Marilyn odniosły ogromny sukces, prowadząc do stałej współpracy IAM oraz Lupy z tym partnerem i torując drogę do Chin (nie tylko do Tianjin Grand Theatre, ale też innych sal) reżyserom młodszego pokolenia. Nie będzie przesadą stwierdzenie, że programerska wizja i odwaga pana Qian Chenga miała kluczowe znaczenie dla zbudowania pozycji polskiego teatru w Chinach $^{8}$.

Chociaż polski teatr zagościł w Chinach w 2011 r. spektaklem Lailonia Teatru Kana wystawionym w ramach Lin Zhaohua Theatre Arts Festival, to dopiero od 2014 r. można mówić o stałych wizytach polskich spektakli na deskach chińskich teatrów. Biorąc pod uwagę liczbę spektakli, recenzji prasowych czy gorący odzew w przestrzeni internetowej, chociażby po premierze Wycinki, można stwierdzić, że Krystian Lupa odgrywa szczególną rolę w szerzeniu wiedzy na temat współczesnego teatru polskiego w Państwie Środka. Zamieszczona niżej tabela 1 zawiera dane dotyczące czasu i miejsca, liczby spektakli i frekwencji na poszczególnych polskich prezentacjach w Azji. Nietrudno zauważyć, że nazwisko Lupy pojawia się w tym zestawieniu najczęściej. Reżyser wystawił w Azji trzy tytuły, w kolejności chronologicznej były to: Persona. Marilyn, Wycinka i Plac Bohaterów. Pojawił się na scenach takich miast, jak: Hongkong, Tianjin, Pekin i Harbin. Jego spektakle w Chińskiej Republice Ludowej i na terenie autonomicznego miasta Hongkong obejrzało podczas czternastu pokazów około 13200 widzów. Oczywiście, nie można pominąc faktu, że prawdziwa krytyka teatralna zaczyna się od naturalnej selekcji, jaką przechodzi każde dzieło w procesie prezentacji trwającej w określonym czasie i mierzącej się z widzem obdarzonym kulturowym kontekstem. Należy jednak zauważyć, że menadżerowie Instytutu Adama Mickiewicza robią wszystko, by zawiązywanie współpracy dokonywało się na polskim, rodzimym gruncie, zaś sami pomysłodawcy projektu nie tylko prezentuja paletę spektakli dostępnych w danym sezonie, lecz dają dyrektorom festiwali i teatrów chińskich wolny wybór z ograniczonego, ale zawsze zawierającego kilka propozycji repertuaru. Pierwsza recepcja spektakli odbywa się w Polsce, co sprawia, że sztuki osadzone w ich naturalnym kontekście są bardziej czytelne dla zagranicznego widza. Tu pojawia się kolejna wattpliwość, a mianowicie, jaki jest stopień wrażliwości na kulturę europejską dyrektorów chińskich teatrów i festiwali teatralnych. Dość przytoczyć komentarz cytowanego już P. Gruszczyńskiego ze wstępu do raportu „Polski teatr w Azji 2012-2016”:

8 Ibidem. 
Tabela 1. Pokazy polskich spektakli teatralnych w Chinach w ramach działań Instytutu Adama Mickiewicza - wykaz chronologiczny*

\begin{tabular}{|c|c|c|c|c|c|c|}
\hline Rok & $\begin{array}{c}\text { Data } \\
\text { pierwszego } \\
\text { spektaklu }\end{array}$ & $\begin{array}{c}\text { Daty } \\
\text { kolejnych } \\
\text { spektakli }\end{array}$ & Kraj & Miasto & Miejsce & $\begin{array}{c}\text { Tytuł } \\
\text { przedstawienia } \\
\text { lub nazwa } \\
\text { projektu }\end{array}$ \\
\hline 2014 & 22.05 .2014 & $23-24.05 .2014$ & Chiny & Tianjin & $\begin{array}{l}\text { Tianjin Grand } \\
\text { Theatre }\end{array}$ & Persona. Marilyn \\
\hline 2014 & 3.09 .2014 & 4.09 .2014 & Chiny & Tianjin & $\begin{array}{l}\text { Tianjin Grand } \\
\text { Theatre }\end{array}$ & $\begin{array}{l}\text { Opera Madame } \\
\text { Curie Elżbiety } \\
\text { Sikory }\end{array}$ \\
\hline 2015 & 4.02 .2015 & 4 i 12.02 .2015 & Indie & $\begin{array}{l}\text { New Delhi, } \\
\text { Agartala, } \\
\text { Mumbaj }\end{array}$ & $\begin{array}{l}\text { Bharat Rang } \\
\text { Mahotsav - festiwal } \\
\text { organizowany przez } \\
\text { National School of } \\
\text { Drama, Agartala, } \\
\text { Kala Ghoda Festival - } \\
\text { venue: Cross Maidan }\end{array}$ & $\begin{array}{l}\text { Zagraj to, çsyli } \\
17 \text { tańcón o casyms }\end{array}$ \\
\hline 2015 & 2.05 .2015 & 3.05 .2015 & Chiny & Tianjin & $\begin{array}{l}\text { Tianjin Grand } \\
\text { Theatre }\end{array}$ & Wycinka \\
\hline 2015 & 6.05 .2015 & 7.05 .2015 & Chiny & Pekin & $21^{\text {st }}$ Century Theatre & Wycinka \\
\hline 2015 & 31.07 .2015 & $1-2.08 .2015$ & Chiny & Pekin & $\begin{array}{l}\text { Beijing People's Art } \\
\text { Theatre }\end{array}$ & Dziady \\
\hline 2015 & 10.10 .2015 & & Japonia & Kioto & $\begin{array}{l}\text { Kyoto Art Center, } \\
\text { ACUA Gallery }\end{array}$ & \begin{tabular}{|l|} 
Sympozjum \\
i wystawa \\
poświęcone \\
Tadeuszowi \\
Kantorowi
\end{tabular} \\
\hline 2015 & 12.10.2015 & & Japonia & Tokio & $\begin{array}{l}\text { Tokyo Metropolitan } \\
\text { Theatre }\end{array}$ & $\begin{array}{l}\text { Sympozjum } \\
\text { „Kantor a teatr } \\
\text { XX w.” }\end{array}$ \\
\hline 2015 & \begin{tabular}{|l|}
14.10 .2015 \\
\end{tabular} & & Chiny & Pekin & $\begin{array}{l}\text { Centralna Akademia } \\
\text { Dramatyczna }\end{array}$ & $\begin{array}{l}\text { Wystawa } \\
\text { Tadeusz Rolke. } \\
\text { Tadeusz Kantor, } \\
\text { Sympozjum } \\
\text { naukowe } \\
\text { o Tadeuszu } \\
\text { Kantorze }\end{array}$ \\
\hline
\end{tabular}

* Szarym kolorem wyróżniono w tabeli spektakle Krystiana Lupy. 


\begin{tabular}{|c|c|c|c|c|}
\hline Krótki opis & Teatr & Reżyser & $\begin{array}{c}\text { Liczba } \\
\text { spektakli }\end{array}$ & Frekwencja \\
\hline \multirow[t]{3}{*}{$\begin{array}{l}\text { Spektakle w ramach Lin Zhaohua/Cao Yu } \\
\text { Festival, pierwsza współpraca IAM z Tianjin } \\
\text { Grand Theatre }\end{array}$} & $\begin{array}{l}\text { Teatr } \\
\text { Dramatyczny } \\
\text { w Warszawie }\end{array}$ & $\begin{array}{l}\text { Krystian } \\
\text { Lupa }\end{array}$ & 3 & 3000 \\
\hline & $\begin{array}{l}\text { Opera } \\
\text { Bałtycka }\end{array}$ & Marek Weiss & 2 & 1500 \\
\hline & $\begin{array}{l}\text { Teatr Dada } \\
\text { von Bzdulów }\end{array}$ & $\begin{array}{l}\text { Leszek Bzdyl } \\
\text { i Katarzyna } \\
\text { Chmielewska }\end{array}$ & 4 & 1800 \\
\hline $\begin{array}{l}\text { Kontynuacja współpracy z Tianjin Grand } \\
\text { Theatre, efekt wizyty studyjnej Qian Chenga } \\
\text { na Boskiej Komedii } 2014\end{array}$ & $\begin{array}{l}\text { Teatr Polski } \\
\text { we Wrocławiu }\end{array}$ & $\begin{array}{l}\text { Krystian } \\
\text { Lupa }\end{array}$ & 2 & 2500 \\
\hline $\begin{array}{l}\text { Kontynuacja wspólpracy z Tianjin Grand } \\
\text { Theatre, efekt wizyty studyjnej Qian Chenga } \\
\text { na Boskiej Komedii } 2014\end{array}$ & $\begin{array}{l}\text { Teatr Polski } \\
\text { we Wrocławiu }\end{array}$ & $\begin{array}{l}\text { Krystian } \\
\text { Lupa }\end{array}$ & 2 & 2500 \\
\hline $\begin{array}{l}\text { Projekt jest efektem wizyty studyjnej } \\
\text { przedstawicieli BPAT w Polsce jesienią } 2014\end{array}$ & $\begin{array}{l}\text { Teatr Polski } \\
\text { we Wrocławiu }\end{array}$ & $\begin{array}{l}\text { Michał } \\
\text { Zadara }\end{array}$ & 3 & 2000 \\
\hline \multicolumn{5}{|l|}{$\begin{array}{l}\text { Obchody 100. rocznicy urodzin Tadeusza } \\
\text { Kantora. Sympozjum poświęcone twórczości } \\
\text { Tadeusza Kantora, w którym wzięli udział } \\
\text { Lech i Barbara Stangretowie oraz Anna } \\
\text { Burzyńska. Sympozjum towarzyszyło } \\
\text { otwarciu wystawy prezentującej rysunki } \\
\text { Kantora oraz prace współczesnych artystów } \\
\text { nawiązujących do jego praktyki }\end{array}$} \\
\hline \multicolumn{5}{|l|}{$\begin{array}{l}\text { Obchody 100. rocznicy urodzin Tadeusza } \\
\text { Kantora. Sympozjum poświęcone twórczości } \\
\text { Tadeusza Kantora, w którym wzięli udział } \\
\text { Lech i Barbara Stangretowie oraz Anna } \\
\text { Burzyńska. Sympozjum towarzyszyło otwarciu } \\
\text { wystawy rysunków Tadeusza Kantora }\end{array}$} \\
\hline $\begin{array}{l}\text { Obchody 100. rocznicy urodzin } \\
\text { Tadeusza Kantora. Sympozjum naukowe } \\
\text { w Centralnej Akademii Dramatycznej } \\
\text { w Pekinie poświęcone twórczości Tadeusza } \\
\text { Kantora, w którym wzięli udział Krzysztof } \\
\text { Miklaszewski, Lech i Barbara Stangretowie } \\
\text { oraz Anna Burzyńska. Sympozjum } \\
\text { towarzyszyło otwarciu wystawy prezentującej } \\
\text { zdjęcia Tadeusza Rolke dokumentujące } \\
\text { działalność teatru Cricot } 2\end{array}$ & & & & \\
\hline
\end{tabular}


Tabela 1. cd.

\begin{tabular}{|c|c|c|c|c|c|c|}
\hline Rok & $\begin{array}{c}\text { Data } \\
\text { pierwszego } \\
\text { spektaklu }\end{array}$ & $\begin{array}{c}\text { Daty } \\
\text { kolejnych } \\
\text { spektakli }\end{array}$ & Kraj & Miasto & Miejsce & $\begin{array}{c}\text { Tytuł } \\
\text { przedstawienia } \\
\text { lub nazwa } \\
\text { projektu }\end{array}$ \\
\hline 2015 & 21.10 .2015 & $23-24.10 .2015$ & Chiny & Wuzhen & $\begin{array}{l}\text { Wuzhen Theatre } \\
\text { Festival }\end{array}$ & $\begin{array}{l}\text { Portrety wiśniowego } \\
\text { sadu }\end{array}$ \\
\hline 2016 & 12.02 .2016 & 15.02 .2016 & Indie & $\begin{array}{l}\text { New Delhi, } \\
\text { Bhubaneswar }\end{array}$ & $\begin{array}{l}\text { Bharat Rang } \\
\text { Mahotsav - festiwal } \\
\text { organizowany przez } \\
\text { National School of } \\
\text { Drama }\end{array}$ & Sonkea \\
\hline 2016 & 8.04 .2016 & 9.04 .2016 & Chiny & Tianjin & $\begin{array}{l}\text { Tianjin Grand } \\
\text { Theatre }\end{array}$ & $\begin{array}{l}\text { Album Karla } \\
\text { Höckera }\end{array}$ \\
\hline 2016 & \begin{tabular}{|l|}
12.04 .2016 \\
\end{tabular} & 13.04 .2016 & Chiny & Harbin & $\begin{array}{l}\text { Harbin Grand } \\
\text { Theatre } \\
\end{array}$ & $\begin{array}{l}\text { Album Karla } \\
\text { Höckera }\end{array}$ \\
\hline 2016 & \begin{tabular}{|l|}
22.04 .2016 \\
\end{tabular} & $23-24.04 .2016$ & Chiny & Tianjin & $\begin{array}{l}\text { Tianjin Grand } \\
\text { Theatre }\end{array}$ & Kryjónka \\
\hline 2016 & 29.04 .2016 & $\begin{array}{l}30.04- \\
1.05 .2016\end{array}$ & Chiny & Harbin & $\begin{array}{l}\text { Harbin Grand } \\
\text { Theatre }\end{array}$ & Kryjowka \\
\hline 2016 & 3.05 .2016 & 4.05 .2016 & Chiny & Tianjin & $\begin{array}{l}\text { Tianjin Grand } \\
\text { Theatre }\end{array}$ & Plac Bohaterón \\
\hline 2016 & 7.05.2016 & 8.05 .2016 & Chiny & Harbin & $\begin{array}{l}\text { Harbin Grand } \\
\text { Theatre }\end{array}$ & Plac Bohaterón \\
\hline 2016 & 3.06 .2016 & 4.06 .2016 & Chiny & Harbin & $\begin{array}{l}\text { Harbin Grand } \\
\text { Theatre } \\
\end{array}$ & (A)pollonia \\
\hline 2016 & 10.06.2016 & 11.06 .2016 & Chiny & Tianjin & $\begin{array}{l}\text { Tianjin Grand } \\
\text { Theatre }\end{array}$ & (A)pollonia \\
\hline 2016 & \begin{tabular}{|l|}
17.06 .2016 \\
\end{tabular} & 18.06 .2016 & Chiny & Tianjin & $\begin{array}{l}\text { Tianjin Grand } \\
\text { Theatre }\end{array}$ & Meczennicy \\
\hline 2016 & 22.06 .2016 & 23.06 .2016 & Chiny & Harbin & $\begin{array}{l}\text { Harbin Grand } \\
\text { Theatre }\end{array}$ & Meczennicy \\
\hline 2016 & 30.09 .2016 & 1.10 .2016 & Korea & Seul & Arko Arts Theatre & Wycinka \\
\hline 2016 & 18.10.2016 & 19.10 .2016 & Chiny & Wuzhen & $\begin{array}{l}\text { Wuzhen Theatre } \\
\text { Festival }\end{array}$ & Wróg ludu \\
\hline 2016 & 21.10 .2016 & 23.10 .2016 & Japonia & Tokio & $\begin{array}{l}\text { Tokyo Metropolitan } \\
\text { Theatre }\end{array}$ & Wycinka \\
\hline 2016 & \begin{tabular}{|l|}
4.11 .2016 \\
\end{tabular} & $5-6.11 .2016$ & Chiny & Pekin & $\begin{array}{l}\text { Beijing People's Art } \\
\text { Theatre }\end{array}$ & Król Lear \\
\hline
\end{tabular}

Źródło: Instytut Adama Mickiewicza, „Polski teatr w Azji 2012-2016”. 


\begin{tabular}{|c|c|c|c|c|}
\hline Krótki opis & Teatr & Reżyser & $\begin{array}{c}\text { Liczba } \\
\text { spektakli }\end{array}$ & Frekwencja \\
\hline $\begin{array}{l}\text { Efekt współpracy z Beijing Fringe } \\
\text { (Meng Jinghui) }\end{array}$ & $\begin{array}{l}\text { Teatr Pieśń } \\
\text { Kozła }\end{array}$ & $\begin{array}{l}\text { Grzegorz } \\
\text { Bral }\end{array}$ & 4 & 720 \\
\hline Kontynuacja współpracy z festiwalem & \begin{tabular}{|l|} 
Teatr \\
Dramatyczny \\
w Białymstoku
\end{tabular} & $\begin{array}{l}\text { Agnieszka } \\
\text { Korytkowska- } \\
\text {-Mazur }\end{array}$ & 2 & 1000 \\
\hline Polski fokus w Tianjin Grand Theatre & $\begin{array}{l}\text { Teatr } \\
\text { Trans-Atlantyk }\end{array}$ & Paul Bargetto & 2 & 900 \\
\hline Polski fokus w Harbin Grand Theatre & \begin{tabular}{|l|} 
Teatr \\
Trans-Atlantyk
\end{tabular} & Paul Bargetto & 2 & 700 \\
\hline Polski fokus w Tianjin Grand Theatre & ne'T'Theatre & Paweł Passini & 5 & 450 \\
\hline Polski fokus w Harbin Grand Theatre & ne'Theatre & Paweł Passini & 5 & 400 \\
\hline $\begin{array}{l}\text { Kontynuacja współpracy Tianjin Grand } \\
\text { Theatre z Krystianem Lupa }\end{array}$ & $\begin{array}{l}\text { Narodowy } \\
\text { Teatr Litewski }\end{array}$ & $\begin{array}{l}\text { Krystian } \\
\text { Lupa }\end{array}$ & 2 & 2500 \\
\hline $\begin{array}{l}\text { Kontynuacja współpracy Tianjin Grand } \\
\text { Theatre z Krystianem Lupą }\end{array}$ & $\begin{array}{l}\text { Narodowy } \\
\text { Teatr Litewski }\end{array}$ & $\begin{array}{l}\text { Krystian } \\
\text { Lupa }\end{array}$ & 2 & 2000 \\
\hline Polski fokus w Harbin Grand Theatre & Nowy Teatr & $\begin{array}{l}\text { Krzysztof } \\
\text { Warlikowski }\end{array}$ & 2 & 2500 \\
\hline Polski fokus w Tianjin Grand Theatre & Nowy Teatr & $\begin{array}{l}\text { Krzysztof } \\
\text { Warlikowski }\end{array}$ & 2 & 1500 \\
\hline Polski fokus w Tianjin Grand Theatre & TR Warszawa & $\begin{array}{l}\text { Grzegorz } \\
\text { Jarzyna }\end{array}$ & 2 & 1800 \\
\hline Polski fokus w Harbin Grand Theatre & TR Warszawa & $\begin{array}{l}\text { Grzegorz } \\
\text { Jarzyna }\end{array}$ & 2 & 700 \\
\hline Spektakl otwarcia festiwalu SPAF & $\begin{array}{l}\text { Teatr Polski } \\
\text { we Wrocławiu }\end{array}$ & $\begin{array}{l}\text { Krystian } \\
\text { Lupa }\end{array}$ & 2 & 949 \\
\hline $\begin{array}{l}\text { Kontynuacja współpracy z Wuzhen, efekt } \\
\text { obecności Meng Jinghui na Boskiej Komedii } \\
2015\end{array}$ & Stary Teatr & Jan Klata & 3 & 3302 \\
\hline Wycinka jako headliner Festival/Tokyo & $\begin{array}{l}\text { Teatr Polski } \\
\text { we Wrocławiu }\end{array}$ & $\begin{array}{l}\text { Krystian } \\
\text { Lupa }\end{array}$ & 3 & 1091 \\
\hline Kontynuacja współpracy z BPAT & Stary Teatr & Jan Klata & 3 & 2313 \\
\hline
\end{tabular}


Instytut (...) zaczął od przywożenia do Polski programatorów, szefów festiwali i dużych ośrodków teatralnych. Pokazywał, tłumaczył, prowadził powoli za rękę wśród meandrów. Nie było to łatwe. Pamiętam, jak podczas festiwalu Boska Komedia siedziałem z grupa, która właśnie zobaczyła Driady. Mieli tyle pytań, że czułem się bezradny, martwiłem się, że nie jestem w stanie wszystkiego wyjaśnić, pokleić wątków w czasie krótkiego spotkania. Myślałem, że co jak co, ale polski dramat romantyczny w Azji nie ma szans. Tymczasem w 2015 r. Džiady w reżyserii Michała Zadary zostały zaproszone i pokazane w Pekinie. Cud?! Nie, mądra strategia promocyjna".

Piotr Gruszczyński opisuje, jak sam go nazywa, „zmasowany atak” Instytutu, wspominając poza wizytami studyjnymi wyjazdy polskich teatralnych rezydentów „na misję" w Chinach. Celem podróży były wykłady o teatrze polskim, których duża część odbyła się w Centralnej Akademii Teatralnej w Pekinie. Wymienia profesora Dariusza Kosińskiego i doktor Annę Burzyńska, których wizyty zaowocowały artykułami w miesięczniku „Drama” („Xiju”). Co więcej, właśnie dzięki zręcznym działaniom IAM pracę Dariusza Kosińskiego Teatra polskie oraz ksiażkę Spotkania z Kantorem Krzysztofa Miklaszewskiego przełożono na język chiński. Ważnym elementem pracy menadżerskiej przy projekcie okazał się też kontakt z prasą. Na premiery zapraszano dziennikarzy i przedstawicieli środowisk artystycznych. Liczba recenzji prasowych, które pojawiły się po spektaklach, wahała się zwykle od kilkunastu do kilkudziesięciu. Jak dotąd, rekord należy do Placu Bobaterón Krystiana Lupy w 2016 r. (59 recenzji).

Gruszczyński podsumowuje działania Instytutu Adama Mickiewicza w sposób jednoznacznie optymistyczny, rozwiewając wszelkie watpliwości dotyczace polityki prowadzenia projektu. Można nie zgadzać się co do wyboru spektakli, wystaw, prelegentów, które Instytut wsparł swoim marketingiem, finansami, wykorzystując przy tym polską flagę i podpisując ja „Skarby z kraju Chopina”"10, można podważać wielość wysiłków włożonych, by wypromować zaledwie kilka nazwisk. Trzeba jednak przyznać, że wszyscy artyści wysłani do Chin, w tym Krystian Lupa, zapisali się w historii polskiego teatru współczesnego jako reprezentanci najwyższej jakości sztuki i od lat sami tworzą międzynarodową markę „Polska”. Trudno nie przyznać racji Gruszczyńskiemu, że „wielkie nazwiska przecierają drogi mniejszym, starzy mistrzowie - młodym adeptom. Lupa czy Warlikowski wywołali pytanie: kto następny?" "11. Przy czym warto pamiętać, że sukces Lupy w Państwie Środka jest poparty sukcesem prężnie działającego zespołu Instytutu Adama Mickiewicza. Trzeba nie lada wysiłku, by w kraju, w którym w zasadzie nie istnieje wolny rynek kultury, promować sztukę ze wszech miar głoszącą hasła wolności słowa, odważnie powracająca

9 Ibidem, s. 13.

10 Nazwa odnosi się do tytułu wystawy polskiej sztuki w Pekinie w 2015 r., którą zorganizował IAM.

11 Instytut Adama Mickiewicza, „Polski teatr w Azji 2012-2016”, s. 13. 
do społecznych traum i artystycznie progresywna. O tym, co zwróciło uwagę, wzruszyło, rozśmieszyło, wryło się w pamięć chińskiego widza, co pozostało niezrozumiałe, o nietypowych skojarzeniach z rodzimą kultura, o jakości prasy recenzenckiej i teatrologicznej w ogóle, będzie mowa w drugiej części artykułu.

\section{Coraz bliżej (Państwa) Środka, czyli Persona. Marylin w Hongkongu i Tianjinie}

W dniach od 11 marca do 5 czerwca 2014 r. w Tianjin Grand Theatre odbyła się pierwsza edycja Tianjin Cao Yu International Theatre Festival. Jak donosi Zhai Zhipeng, dziennikarz „Tianjin Daily”, w reportażu pod doniosłym tytułem Teatr, który niesie blask miastu:

Wiele osobistości ze świata kultury, w tym reżyserzy Lin Zhaohua, Tian Qinxin, Meng Jinhui, Li Liuyi, dramatopisarze Guo Shixing, Xu Ying, Li Longyin oraz scenografowie Gao Guangjian i Tan Shaoyuan, przybyło z Pekinu, Szanghaju i Xi’anu, by obejrzeć spektakle. Festiwal był relacjonowany blisko 30 razy przez „People’s Daily”, „Beijing Daily”, „Beijing Youth Daily” i „Beijing Evening News”. Chociaż festiwal się skończyl, dyskusja wciąż trwa ${ }^{12}$.

Wśród dwunastu zaprezentowanych sztuk znalazło się pięć zagranicznych, w tym Persona. Marilyn Krystiana Lupy. Nie była to pierwsza prezentacja tego spektaklu w Chinach. Skrótowy zarys wydarzeń, które doprowadziły do jego pokazów na terenie Chińskiej Republiki Ludowej, nie licząc rządzącego się inną polityką wewnętrzną regionu autonomicznego Hongkong, przedstawiłam wyżej. Opis ten wart jest jednak rozszerzenia o głos głównego organizatora wyjazdów polskich twórców do Chin, menadżera Projektu Azja Marcina Jacoby’ego, z którym, dla celów badawczych, przeprowadziłam półtoragodzinny wywiad. Treść wywiadu przybliża wiele czynności organizacyjnych, które miały bezpośredni wpływ na sukces Krystiana Lupy w Chinach. Pokazuje też, że działania promocyjne Instytutu Adama Mickiewicza opierają się na skutecznie rozwijanych relacjach na poziomie decydentów, a istotne znaczenie ma tu głębokie zrozumienie kultury, z której pochodzą owi decydenci.

Niespełna 7 miesięcy przed Tianjin Cao Yu International Theatre Festival Krystian Lupa pokazał spektakl o amerykańskiej ikonie kina podczas World Cultures Fesival w Hongkongu. Jednak droga polskiego teatru do autonomicznego Hongkongu była długa i wyboista. Jeszcze w 2009 r., kiedy odbyła się pierwsza wizyta

12 Zhai Zhipeng, Xiju, dai gei yi zuo chengshi de jingcai [Teatr, który niesie blask miastu], http:// news.163.com/14/0612/08/9UHB32BP00014AED.html (dostęp: 20.05.2017); tłum. własne. 
studyjna dyrektorów najważniejszych scen Chińskiej Republiki Ludowej w Polsce, jakikolwiek pokaz polskiego teatru w Państwie Środka wydawał się tylko pieśnia przyszłości. Marcin Jacoby, planujący wówczas pierwsze kroki dla realizacji Projektu Azja w Chinach, tak wspomina reakcję chińskich dyrektorów, którym w ciągu kilku dni przedstawiono najważniejszy polski dorobek teatralny roku:

\begin{abstract}
Powiedzieli, że absolutnie ich to nie interesuje, że kompletnie nie rozumieja, jak można robić sztuki, które nie mają budującej energii i kultury, która pokazuje, że ludzie są szczęśliwi i radośni. Miałem wrażenie, że nie ruszymy tematu teatru w Chinach, dopóki szefami teatru są osoby, które uważają że teatr ma być pozytywny, ma wspomagać propagandę i władzę w roli edukacyjnej, ma być rozumiany jako narzędzie prania mózgu ${ }^{13}$.
\end{abstract}

Następne lata, kiedy Jacoby skupił się głównie na budowaniu relacji kulturalnych z Korea, przyniosły wydarzenia niespodziewanie zmieniające kierunek starań związanych z nawiązywaniem współpracy teatralnej z Azją. W 2012 r. na Hong Kong Arts Festival zaproszono spektakl 4.48 Psychosis Grzegorza Jarzyny. Ponieważ na widowni znaleźli się jednocześnie Marcin Jacoby oraz Elaine Yeung, dyrektor Hong Kong Leisure and Cultural Services Department, instytucji prężnie zarządzającej obiektami kulturalnymi Hongkongu, w efekcie obustronnego zainteresowania współpracą zorganizowano wizytę studyjną w Polsce. Jej celem miało być przedstawienie kolejnych propozycji mogących zasilić repertuar festiwalowy Specjalnego Regionu Administracyjnego Hongkong. Zainteresowanie Elaine Yeung współpracą było ugruntowane założeniami World Cultures Festival, którego odsłona w 2013 r. miała skupiać się na współczesnych trendach teatralnych Europy Środkowo-Wschodniej. Po obejrzeniu licznych prezentacji polskiego teatru Elaine Yeung ostatecznie zdecydowała się zaprosić na festiwal spektakl Lupy Persona. Marilyn. Sytuacja, jak wspomina Jacoby, była o tyle trudna, że spektakl był produkcja Teatru Dramatycznego, który w czasie negocjacji z Chinami był w krytycznej sytuacji, zarówno pod względem finansowym, kadrowym, jak i prawnym. Reaktywacja produkcji i wysłanie jej do Hongkongu stanowiło więc nie lada wyzwanie. Po kolejnych rozmowach z nowym dyrektorem Teatru Dramatycznego ostatecznie udało się wysłać sztukę do Chin, ale o sukcesie pokazów sam Jacoby mówi chłodno:

Sukces spektaklu był raczej umiarkowany, towarzyszyły mu niepełne sale, nie było dużego odzewu w prasie, miałem nawet wrażenie, że zmarnowaliśmy świetnego reżysera i świetną produkcję na wydarzenie, które w zasadzie nie miało sensu, za to po raz pierwszy udało nam się namówić Krystiana Lupę, by pokazał spektakl w sali, która ma siedemset, osiemset miejsc. Do tej pory, gdy wysyłaliśmy jego produkcje do innych miejsc, nie zgadzał się na to ${ }^{14}$.

13 Wywiad z Marcinem Jacobym przeprowadzony przez autorkę artykułu w Instytucie Adama Mickiewicza w Warszawie w dniu 6.02.2017 r.

14 Ibidem. 
Wydarzenia kolejnych miesięcy pokazały, że prezentacja w Hongkongu była strategicznym elementem budowania mostu między teatralną Polską a Chińską Republiką Ludowa. Dzięki kontaktom z Instytutem Polskim w Pekinie podczas kolejnej wizyty w Chinach Jacoby odwiedził nowo powstały Grand Theatre w Tianjinie, gdzie poznał osobę, która na drodze kariery Krystiana Lupy w Chinach miała odtąd kluczowe znaczenie. Niedługo przed tym spotkaniem przetarg mający na celu wyłonienie zarządcy nowego teatru w Tianjinie, dzięki niezaprzeczalnemu argumentowi finansowemu, wygrała prywatna firma Propel z dyrektorem Qian Chengiem na czele. Historia zarządzania teatrem przez agencje marketingową Propel, która nigdy wcześniej nie miała do czynienia z tak dużym obiektem, mogłaby skończyć się niepowodzeniem, gdyby nie sam Qian Cheng, były dyrektor Beijing Concert Hall, najbardziej reprezentacyjnego i najważniejszego obiektu wśród sal koncertowych w całych Chinach. Według Jacoby'ego „Qian Cheng był w Beijing Concert Hall człowiekiem wielkiego sukcesu do momentu, kiedy w efekcie niezwykle nieprzejrzystego procesu prawnego został usunięty z życia publicznego na wiele lat, by w końcu pojawić się jako szef firmy Propel”"15. Qian Cheng w wywiadzie Za co Chincayycy cenia polski teatr dla portalu Culture.pl ujawnia szczegóły tych wydarzeń:

Zanim zostałem szefem sali koncertowej, dawała ona około 60 koncertów rocznie. Pod koniec lat 90., kiedy rząd wprowadził dwa dni wolne od pracy, już 510! Przy jednej sali i jednej scenie! Graliśmy koncerty popołudniami i wieczorami, organizowaliśmy otwarte dni klasyczne, a bilety, także te stojące, sprzedawały się świetnie! I wtedy przyszła nowa kadra, a wraz z nią nowe problemy i pomysły na zarządzanie salą koncertową. To był czas trudnych rozmów, sytuacja pogarszała się każdego dnia. W międzyczasie zostałem dyrektorem Sali Koncertowej Zakazanego Miasta w Pekinie oraz Teatru Wielkiego Centrum Kultury i Sztuki w Nankinie. Zostałem też wiceszefem Chińskiej Orkiestry Narodowej. Niestety moje umiejętności menadżerskie okazały się, jak widać, niewystarczające i po półtora roku kierowania orkiestrą zostałem aresztowany i osadzony w więzieniu na 5 lat. To była głośna, szeroko komentowana w świecie kultury sprawa. Kiedy wyszedłem z aresztu w 2006 r., nie było już dla mnie miejsca w Pekinie. Wróciłem więc do Tianjinu i tam od podstaw zacząłem organizować wydarzenia kulturalne w dziedzinie teatru, muzyki, opery ${ }^{16}$.

Dygresje dotyczace kariery zawodowej Qian Chenga oraz historia przejęcia teatru przez prywatną firmę Propel byłyby zbędne, gdyby nie świadomość, że w tym splocie zdarzeń, jak to przeważnie bywa w Chinach, przetarg na zarządzanie Tianjin Grand Theatre mogła wygrać firma rządowa, co z kolei mogłoby unicestwić szansę pokazania dwóch, zarówno pod względem formy, jak i treści, niezwykle odważnych sztuk Krystiana Lupy w Tianjinie. Co godne uwagi, Tianjin jest miastem portowym, oddalonym zaledwie kilkadziesiąt kilometrów od stolicy Chińskiej Republiki Ludowej,

\footnotetext{
15 Ibidem.

16 Qian Cheng, Za co Chincsycy cenia polski teatr?, rozmawiali: M. Jacoby, A. Legierska, http:// culture.pl/pl/artykul/za-co-chińczycy-cenią-polski-teatr (dostęp: 23.05.2017).
} 
gdzie nadzór cenzorski jest najbardziej rygorystyczny. Jeśli nawet, po wielu zmianach cenzorskich, doszłoby do prezentacji Persony. Marilyn czy Wycinki w Tianjinie, echo tychże pokazów, jak zgaduję, w najmniejszym stopniu nie mogłoby się równać z reperkusjami, jakie wywołało organizatorskie wsparcie Qian Chenga.

Przez lata mozolnie zdobywane przez Qian Chenga kontakty z osobistościami ze świata kultury zaowocowały utworzeniem festiwalu, który, zasilony w najbardziej rozpoznawalne postaci krytyki teatralnej, stał się świetnie przygotowaną pod względem promocyjnym przestrzenią do szerokiej dyskusji o spektaklach polskiego reżysera. Qian Cheng, który postawił sobie za cel pokazanie w przemysłowym Tianjinie najlepszego teatru światowego, mimo że jego wizja przypominała bardziej mit o szklanych domach niż plan strategiczny dla obiektu kulturalnego Chińskiej Republiki Ludowej, w 2014 r. zaczął realizację swego planu od zaproszenia do Tianjinu teatrów zagranicznych na pierwszą edycję Cao Yu International Theatre Festival.

Niezależnie od tego, jak szerokie kręgi zataczają znajomości organizatora (chin. guanxi), choć mają one niemałe znaczenie, to procedury związane z dopuszczeniem zagranicznej sztuki do publicznych pokazów w Chinach są długie i skomplikowane:

\begin{abstract}
Każda produkcja artystyczna chcąca zaprezentować się w Chinach musi dostarczyć cenzurze nagranie z tłumaczeniem. Wszystkie słowa, niezależnie czy jest to teatr, czy muzyka, czy nucony pod nosem tekst, muszą być przetłumaczone. Cenzor, oglądając nagranie, zwraca uwage na sprawy nie tylko polityczne, ale przede wszystkim obyczajowe. Kiedy cenzor dopuści treść pokazu, przed upublicznieniem realizacji jest jeszcze długa ścieżka formalności, zdobywania pieczątek, prezentowania umów. Jest to bardzo długi, bolesny i niepewny proces ${ }^{17}$.
\end{abstract}

Mimo że w ocenie zagranicznych obserwatorów Chiny wydają się administracyjnie scentralizowane, każda prowincja prowadzi w rzeczywistości odmienna politykę kulturalna, w każdej prowincji też cenzura działa w innym stopniu. Najbardziej restrykcyjny jest pod tym względem Pekin, co daje odpowiedź, czemu Projektowi Azja od lat najtrudniej przebić się z treścią polskiej kultury właśnie na scenę pekińską. Mimo bliskości miast, Tianjin, dzięki osobie dyrektora Qian Chenga, zaczął budować scenę bogatą w nową jakość teatralną, przesunął też granicę dopuszczalności treści obyczajowych na tyle, że Krystian Lupa i kilku innych zagranicznych reżyserów uznało ingerencję cenzorską za nienaruszającą podstawowych założeń dzieł. Co więcej, rodzaj zupełnie ponadkulturowego zrozumienia między Qian Chengiem i Krystianem Lupa zaowocował długoterminową współpraca, której kontynuacja trwa do dziś. Qian Cheng, będący brawurowym wręcz promotorem własnych planów proteatralnych, „,rozpisał na kilka lat projekt promocji Krystiana Lupy w swoim teatrze, jako wielkiego reżysera światowego"18.

17 Instytut Adama Mickiewicza, „Polski teatr w Azji 2012-2016”.

18 Ibidem. 
Warunki, które zbiegły się w czasie i miały wpływ na możliwość pokazania Persony. Marilyn Krystiana Lupy na terenie Chińskiej Republiki Ludowej, a także na jakość odbioru spektaklu, odzew prasowy, skalę ingerencji cenzorskiej i szansę zasilenia widowni w środowiska związane z teatrem i kulturą w ogóle, można zakwalifikować jako kontekst promocyjny. Choć kultura, jak żadna inna dziedzina, prosi się o obiektywny entourage, kontekst ten jest nieunikniony, zwłaszcza gdy mowa o transmisji polskiego teatru do kraju, w którym reżim kulturowy ma tak długą tradycję, że stworzył w zasadzie alternatywną do tej ukrytej w prywatnych szufladach, prywatnych rozmowach czy prywatnych podróżach rzeczywistość kulturowa.

W Chinach relacje interpersonalne często są ważniejsze od rygoru prawa, a biorąc pod uwagę nieporównywalnie większą od europejskiej skalę wszystkich działań kulturalno-rozrywkowych, ryzyko finansowe podejmowanych przedsięwzięć wymaga inwestycji prywatnych przedsiębiorców. W efekcie w państwie tym mamy do czynienia $z$ dwoma schematami organizacyjnymi - w pierwszym silnie cenzurowana kultura staje się narzędziem wspierającej ją finansowo władzy, w drugim kulturę ,prywatyzuje się" i upowszechnia w komercyjnym procesie sprzedażowym. Historia Qian Chenga i Tianjin Grand Theatre jest przykładem wolnego od brzemienia rządowej, komunistycznej propagandy schematu „prywatyzacji” zarówno instytucji teatru, jak i treści teatralnych. Schemat ten jest być może korzystny dla zapraszanych do współpracy twórców i prywatnych mecenasów tejże kultury, ale ma też swoje słabe strony. Mimo że działanie w jego ramach daje szansę na odrobinę wolności, to podmiotem decyzyjnym są najczęściej przedsiębiorcy, którzy próbują przede wszystkim zarobić, kierują się własnymi odczuciami, zwłaszcza wyczuciem tego, co na rynku sztuki zaspokoi głód nowości, a jednocześnie będzie przyswajalne dla szerokiego grona odbiorców.

Qian Cheng, biorąc pod uwagę jego doświadczenie w promowaniu sztuki i zainteresowanie, jakim obdarza światowy teatr, nie jest tylko świetnie oceniającym potrzeby rynku biznesmenem. Jest również menadżerem o wrażliwości pozwalającej zrozumieć teatr poza kontekstem kraju, w którym ten teatr powstaje. Podąża za intuicja, która pozwala zainwestować w dobrą sztukę, mimo że inwestycja ta jest na granicy ryzyka. W obliczu kończącego się kolejnymi sukcesami procesu kształtowania twórczej sylwetki Krystiana Lupy w Tianjin Grand Theatre pojawia się pytanie, dlaczego pierwszy pokaz Persony. Marilyn w Hongkongu nie miał widocznego odzewu prasowego, natomiast po premierze spektaklu w Tianjinie odzew ten był nieporównywalnie większy. Odpowiedź tkwi zarówno w działaniach promocyjnych Instytutu Adama Mickiewicza i Tianjin Grand Theatre, jak i zapotrzebowaniu repertuarowym stosunkowo liberalnego politycznie i kulturowo widza z Hongkongu oraz widza Chińskiej Republiki Ludowej, który jest przyzwyczajony do oglądania sztuki przez gruby filtr politycznej poprawności. Wydaje się, że długo niezaspokajana potrzeba kulturowej wolności budzi zupełnie inną tęsknotę estetyczną i łaknienie treści o nieporuszanej do tej pory tematyce. Zapotrzebowanie to najwyraźniej pokazują recenzje prasowe, o których będzie mowa w drugiej części artykułu. 
SUMMARY

\section{THE SUCCESS OF KRYSTIAN LUPA'S PERFORMANCES "PERSONA. MARYLIN" AND "WYCINKA" [WOODCUTTERS] IN MAINLAND CHINA: THE ANALYSIS OF THE PHENOMENON BASED ON THE ORGANIZERS' REPORTS}

The research purpose was to examine the success of the Polish stage director Krystian Lupa's performances presented in mainland China. The content of the study was divided into two separate articles. In the first article "The success of Polish stage director Krystian Lupa's performances "Persona. Marylin" and "Wycinka" [Woodcutters] in mainland China - analysis of the phenomenon based on the organizers' report", the main source of research is the interview with Marcin Jacoby, who at that time was the manager of the Asia Project in the Adam Mickiewicz Institute, which is a prime mover of Polish contemporary theatre display in China. Lupa's performances in China were displayed in Hong Kong at first, but at that time did not achieve any success. While the Chinese people were used to theatre involved in social issues, sated with a constructive image of the world and the place of the individual within society, Polish theatre plays encountered all-encompassing misapprehension. As Polish organisers often mentioned in media, the base for the breakthrough was a collaboration with the director of the newly-created Tianjin Grand Theatre, who invited Kristian Lupa with his "Persona: Marilyn" to continental China for the first time, while at the same time taking care of very good promotion and media coverage. In the first article, all "back room" activities that could contribute to success of Lupa's performances in China were included. An unveiling of these arrangements can help the reader understand what constitutes a success of polish modern theatre in China. 